\title{
Common fixed point under contractive condition of Ćirić's type on cone metric type spaces
}

\author{
Marija P Stanić ${ }^{*}$, Aleksandar S Cvetković ${ }^{2}$, Suzana Simić ${ }^{1}$ and Sladjana Dimitrijević
}

\footnotetext{
* Correspondence: stanicm@kg.ac. rs

${ }^{1}$ Department of Mathematics and Informatics, Faculty of Science, University of Kragujevac, Radoja Domanovića 12, 34000 Kragujevac, Serbia

Full list of author information is available at the end of the article
}

\begin{abstract}
The purpose of this article is to generalize common fixed point theorems under contractive condition of Cirić's type on a cone metric type space. We give basic facts about cone metric type spaces, and we prove common fixed point theorems under contractive condition of Ćirićs type on a cone metric type space without assumption of normality for cone. As special cases we get the corresponding fixed point theorems on a cone metric space with respect to a solid cone. Obtained results in this article extend, generalize, and improve, well-known comparable results in the literature.
\end{abstract}

2000 Mathematics Subject Classification: 47H10; 54H25; 55M2O.

Keywords: cone metric type space, solid cone, coincidence point, point of coincidence, common fixed point

\section{Introduction}

Replacing the real numbers, as the co-domain of a metric, by an ordered Banach space we obtain a generalization of metric space (see, e.g., [1-3]). Huang and Zhang [4] reintroduced such spaces under the name of cone metric spaces. They described the convergence in cone metric space, introduced their completeness and proved some fixed point theorems for contractive mappings. Cones and ordered normed spaces have some applications in optimization theory (see $[5,6]$ ). The initial study of Huang and Zhang [4] inspired many authors to prove fixed point theorems, as well as common fixed point theorems for two or more mappings on cone metric space, e.g., [7-18].

In [19], a generalization of a cone metric space, called a cone metric type space was considered, and some common fixed point theorems for four mappings in such space were proved. Common fixed point theorem under contractive condition of Cirić's type (see [20]) on cone metric space in settings of a normal cone was proved in [21]. In this article, we extend that result proving common fixed point theorems under contractive condition of Cirić's type on a cone metric type space without assumption of normality for cone. As special cases we get the corresponding fixed point theorems in a cone metric space with respect to a solid cone.

The article is organized as follows. In Section 2, we repeat some definitions and well known results which will be needed in the sequel. In Section 3, we prove common fixed point theorems on a cone metric type space and present some corollaries. 


\section{Definitions and notation}

Let $E$ be a real Banach space and $P$ be a subset of $E$. By $\theta$ we denote zero element of $E$ and by int $P$ the interior of $P$. The subset $P$ is called $a$ cone if and only if:

(i) $P$ is closed, nonempty and $P \neq\{\theta\}$;

(ii) $a, b \in \mathbb{R}, a, b \geq 0$, and $x, y \in P$ imply $a x+b y \in P$;

(iii) $P \cap(-P)=\{\theta\}$.

For a given cone $P$, a partial ordering $\leqslant$ with respect to $P$ is introduced in the following way: $x \leqslant y$ if and only if $y-x \in P$. In order to indicate that $x \leqslant y$, but $x \neq y$, we write $x<y$. If $y-x \in$ int $P$, we write $x \ll y$.

The cone $P$ is called normal if there is a number $k>0$, such that, for all $x, y \in E, \theta \leqslant$ $x \leqslant y$ implies $\|x\| \leq k\|y\|$. If a cone is not normal, it is called non-normal.

If int $P \neq \varnothing$, the cone $P$ is called solid.

In the sequel, we always suppose that $E$ is a real Banach space, $P$ is a solid cone in $E$, and $\leqslant$ is partial ordering with respect to $P$.

Definition 2.1. ([19]) Let $X$ be a nonempty set and $E$ be a real Banach space with cone $P$. A vector-valued function $d: X \times X \rightarrow E$ is said to be a cone metric type function on $X$ with constant $K \geq 1$, if the following conditions are satisfied:

$(d 1) \theta \leqslant d(x, y)$ for all $x, y \perp X$ and $d(x, y)=\theta$ if and only if $x=y$;

$\left(d_{2}\right) d(x, y)=d(y, x)$ for all $x, y \perp X$

$\left(d_{3}\right) d(x, y) \leqslant K(d(x, z)+d(z, y))$ for all $x, y, z L X$.

The pair $(X, d)$ is called a cone metric type space (in brief CMTS).

Remark 2.1. For $K=1$ in Definition 2.1 we obtain a cone metric space introduced in [4].

Definition 2.2. Let $(X, d)$ be a CMTS and $\left\{x_{n}\right\}$ be a sequence in $X$.

$\left(c_{1}\right)\left\{x_{n}\right\}$ converges to $x L X$ if for every $c L E$ with $\theta \ll c$ there exists $n_{0} \in \mathbb{N}$ such that $d\left(x_{n}, x\right) \ll c$ for all $n<n_{0}$. We write $\lim _{n \rightarrow \infty} x_{n}=x$, or $x_{n} \rightarrow x, n \rightarrow \infty$.

$\left(c_{2}\right)$ If for every $c L E$ with $\theta \ll c$, there exists $n_{0} \in \mathbb{N}$ such that $d\left(x_{n}, x_{m}\right) \ll c$ for all $n, m>n_{0}$, then $\left\{x_{n}\right\}$ is called a Cauchy sequence in $X$.

If every Cauchy sequence is convergent in $X$, then $X$ is called a complete CMTS.

Remark 2.2. If $(X, d)$ is a cone metric space (i.e., CMTS with $K=1$ ) relative to a normal cone $P$, then a sequence $\left\{x_{n}\right\}$ in $X$ converges to $x L X$ if and only if $d\left(x_{n}, x\right) \rightarrow \theta$, $n \rightarrow \infty$, i.e., if and only if $\left\|d\left(x_{w}, x\right)\right\| \rightarrow 0, n \rightarrow \infty$ (see [[4], Lemma 4] ). Further, $\left\{x_{n}\right\}$ in $X$ is a Cauchy sequence if and only if $d\left(x_{n}, x_{m}\right) \rightarrow \theta, n, m \rightarrow \infty$, i.e., if and only if $\|_{d}$ $\left(x_{n}, x_{m}\right) \| \rightarrow 0, n, m \rightarrow \infty$ (see [[4], Lemma 4]).

In the case of a non-normal cone equivalences in previous statements do not hold. For a non-normal cone $d\left(x_{n}, x\right) \rightarrow \theta, n \rightarrow \infty$ implies $x_{n} \rightarrow x, n \rightarrow \infty$, and $d\left(x_{m}, x_{n}\right) \rightarrow \theta, m$, $n \rightarrow \infty$ implies that $\left\{x_{n}\right\}$ is a Cauchy sequence.

Example 2.1. ([19]) Let $B=\left\{e_{i} \mid i=1, \ldots, n\right\}$ be orthonormal basis of $\mathbb{R}^{n}$ with inner product $(\cdot, \cdot)$. Let $p>0$ and

$$
X_{p}=\left\{\left.[x]\left|x:[0,1] \rightarrow \mathbb{R}^{n}, \int_{0}^{1}\right|\left(x(t), e_{k}\right)\right|^{p} \mathrm{~d} t \in \mathbb{R}, k=1, \ldots, n\right\},
$$


where $[x]$ represents class of element $x$ with respect to equivalence relation of functions equal almost everywhere. If we choose $E=\mathbb{R}^{n}$ and

$$
P_{B}=\left\{y \in \mathbb{R}^{n} \mid\left(y, e_{i}\right) \geq 0, i=1, \ldots, n\right\}
$$

then $P_{B}$ is a solid cone. For $d: X_{p} \times X_{p} \rightarrow P_{B}$ defined by

$$
d(f, g)=\sum_{i=1}^{n} e_{i} \int_{0}^{1}\left|\left((f-g)(t), e_{i}\right)\right|^{p} \mathrm{~d} t, f, g \in X_{p},
$$

$\left(X_{p}, d\right)$ is CMTS with $K=2^{p-1}$.

The following properties hold in the case of a CMTS.

Lemma 2.1. Let $(X, d)$ be a CMTS over ordered real Banach space E with a cone $P$. The following properties hold $(a, b, c L E)$ :

$\left(p_{1}\right)$ If $a \leqslant b$ and $b \ll c$, then $a \ll c$.

$\left(p_{2}\right)$ If $\theta \leqslant a \ll c$ for all $c L$ int $P$, then $a=\theta$.

$\left(p_{3}\right)$ If $a \leqslant \lambda a$, where $a L P$ and $0 \leq \lambda<1$, then $a=\theta$.

$\left(p_{4}\right)$ Let $x_{n} \rightarrow \theta$ in $E$ and let $\theta \ll c$. Then there exists positive integer $n_{0}$ such that $x_{n}$ $\ll c$ for each $n>n_{0}$.

\section{Fixed point theorems}

Theorem 3.1. Let $(X, d)$ be a complete CMTS with constant $K L[1,2]$ relative to a solid cone $P$. Let $\{F, T\}$ be a pair of self-mappings on $X$ such that for some constant $\lambda L(0,1 /$ (2K)) for all $x, y L X$ there exists

$$
u(x, y) \in\{d(x, y), d(x, F x), d(y, T y), d(x, T y), d(y, F x)\},
$$

such that the following inequality

$$
d(F x, T y) \preceq \lambda u(x, y)
$$

holds. Then $F$ and $T$ have a unique common fixed point.

Proof. Let us choose $x_{0} L X$ arbitrary and define sequence $\left\{x_{n}\right\}$ as follows: $x_{2 n+1}=$ $F x_{2 w}, x_{2 n+2}=T x_{2 n+1}, n=0,1,2, \ldots$. We shall show that

$$
d\left(x_{k+1}, x_{k}\right) \preceq \alpha d\left(x_{k}, x_{k-1}\right), k \geq 1,
$$

where $\alpha=\lambda K /(1-\lambda K)$ (since $\lambda K<1 / 2$, it is easy to see that $\alpha L(0,1))$. In order to prove this, we consider the cases of an odd integer $k$ and of an even $k$.

For $k=2 n+1$, from (3.2) we have

$$
d\left(x_{2 n+2}, x_{2 n+1}\right)=d\left(F x_{2 n}, T x_{2 n+1}\right) \preceq \lambda u\left(x_{2 n}, x_{2 n+1}\right),
$$

where, according to (3.1),

$$
\begin{aligned}
u\left(x_{2 n}, x_{2 n+1}\right) \in & \left\{d\left(x_{2 n}, x_{2 n+1}\right), d\left(x_{2 n}, F x_{2 n}\right), d\left(x_{2 n+1}, T x_{2 n+1}\right),\right. \\
& \left.d\left(x_{2 n}, T x_{2 n+1}\right), d\left(x_{2 n+1}, F x_{2 n}\right)\right\} \\
= & \left\{d\left(x_{2 n}, x_{2 n+1}\right), d\left(x_{2 n+1}, x_{2 n+2}\right), d\left(x_{2 n}, x_{2 n+2}\right), \theta\right\}
\end{aligned}
$$

Thus, we get the following cases: 
- $d\left(x_{2 n+2}, x_{2 n+1}\right) \leqslant \lambda d\left(x_{2 n+1}, x_{2 n+2}\right)$, which, according to $\left(p_{3}\right)$, implies $d\left(x_{2 n+1}, x_{2 n+2}\right)$

$=\theta$;

- $d\left(x_{2 n+2}, x_{2 n+1}\right) \leqslant \lambda d\left(x_{2 n}, x_{2 n+1}\right)$;

- $d\left(x_{2 n+2}, x_{2 n+1}\right) \leqslant \lambda d\left(x_{2 n}, x_{2 n+2}\right)$, that is, because of $\left(d_{3}\right)$,

$$
d\left(x_{2 n+2}, x_{2 n+1}\right) \preceq \lambda K\left(d\left(x_{2 n}, x_{2 n+1}\right)+d\left(x_{2 n+1}, x_{2 n+2}\right)\right),
$$

which implies

$$
d\left(x_{2 n+2}, x_{2 n+1}\right) \preceq \frac{\lambda K}{1-\lambda K} d\left(x_{2 n}, x_{2 n+1}\right) .
$$

Hence, (3.3) is satisfied, where $\alpha=\max \{\lambda, \lambda K /(1-\lambda K)\}=\lambda K /(1-\lambda K)$.

Now, for $k=2 n+2$,we have

$$
d\left(x_{2 n+3}, x_{2 n+2}\right)=d\left(F x_{2 n+2}, T x_{2 n+1}\right) \preceq \lambda u\left(x_{2 n+2}, x_{2 n+1}\right),
$$

where

$$
\begin{aligned}
u\left(x_{2 n+2}, x_{2 n+1}\right) \in & \left\{d\left(x_{2 n+2}, x_{2 n+1}\right), d\left(x_{2 n+2}, F x_{2 n+2}\right), d\left(x_{2 n+1}, T x_{2 n+1}\right),\right. \\
& \left.d\left(x_{2 n+2}, T x_{2 n+1}\right), d\left(x_{2 n+1}, F x_{2 n+2}\right)\right\} \\
= & \left\{d\left(x_{2 n+2}, x_{2 n+1}\right), d\left(x_{2 n+2}, x_{2 n+3}\right), \theta, d\left(x_{2 n+1}, x_{2 n+3}\right)\right\},
\end{aligned}
$$

and we get the following cases:

- $d\left(x_{2 n+3}, x_{2 n+2}\right) \leqslant \lambda d\left(x_{2 n+2}, x_{2 n+1}\right)$;

- $d\left(x_{2 n+3}, x_{2 n+2}\right) \leqslant \lambda d\left(x_{2 n+3}, x_{2 n+2}\right)$, which gives $d\left(x_{2 n+3}, x_{2 n+2}\right)=\theta$;

- $d\left(x_{2 n+3}, x_{2 n+2}\right) \leqslant \lambda d\left(x_{2 n+3}, x_{2 n+1}\right) \leqslant \lambda K\left(d\left(x_{2 n+3}, x_{2 n+2}\right)+d\left(x_{2 n+2}, x_{2 n+1}\right)\right)$, which implies

$$
d\left(x_{2 n+3}, x_{2 n+2}\right) \preceq \frac{\lambda K}{1-\lambda K} d\left(x_{2 n+2}, x_{2 n+1}\right) .
$$

So, inequality (3.3) is satisfied in this case, too.

Therefore, (3.3) is satisfied for all $k \in \mathbb{N}_{0}$, and by iterating we get

$$
d\left(x_{k}, x_{k+1}\right) \preceq \alpha^{k} d\left(x_{0}, x_{1}\right) .
$$

Since $K \geq 1$, for $m>k$ we have

$$
\begin{aligned}
d\left(x_{k}, x_{m}\right) & \preceq K d\left(x_{k}, x_{k+1}\right)+K^{2} d\left(x_{k+1}, x_{k+2}\right)+\cdots+K^{m-k-1} d\left(x_{m-1}, x_{m}\right) \\
& \preceq\left(K \alpha^{k}+K^{2} \alpha^{k+1}+\cdots+K^{m-k} \alpha^{m-1}\right) d\left(x_{0}, x_{1}\right) \\
& \preceq \frac{K \alpha^{k}}{1-K \alpha} d\left(x_{0}, x_{1}\right) \rightarrow \theta, \text { as } k \rightarrow \infty .
\end{aligned}
$$

Hence, $\left\{x_{k}\right\}$ is a Cauchy sequence in $X$ (it follows, by $\left(p_{4}\right)$ and $\left(p_{1}\right)$, that for every $c \in$ int $P$ there exists positive integer $k_{0}$ such that $d\left(x_{k} x_{m}\right) \ll c$ for every $\left.m>k>k_{0}\right)$.

Since $X$ is complete CMTS, there exists $v \in X$ such that $x_{k} \rightarrow v$, as $k \rightarrow \infty$. Let us show that $F v=T v=v$. We have $d\left(F x_{2 w}, T v\right) \leqslant \lambda u\left(x_{2 w}, v\right)$, where

$$
u\left(x_{2 n}, v\right) \in\left\{d\left(x_{2 n}, v\right), d\left(x_{2 n}, F x_{2 n}\right), d(v, T v), d\left(x_{2 n}, T v\right), d\left(v, F x_{2 n}\right)\right\} .
$$


Thus, for any $\theta \ll c$ and sufficiently large $n$, at least one of the following cases hold:

$$
\begin{aligned}
& \cdot d\left(F x_{2 n}, T v\right) \preccurlyeq \lambda d\left(x_{2 n}, v\right) \ll \lambda \cdot c / \lambda=c ; \\
& \cdot d\left(F x_{2 n} T v\right) \leqslant \lambda d\left(x_{2 n}, F x_{2 n}\right) \text {, i.e., } \\
& d\left(F x_{2 n}, T v\right) \preceq \lambda K d\left(x_{2 n}, v\right)+\lambda K d\left(v, x_{2 n+1}\right) \ll \lambda K \frac{c}{2 \lambda K}+\lambda K \frac{c}{2 \lambda K}=c ; \\
& \text { - } d\left(F x_{2 n}, T v\right) \preccurlyeq \lambda d(v, T v) \preccurlyeq \lambda K\left(d\left(v, F x_{2 n}\right)+d\left(F x_{2 n}, T v\right)\right), \text { i.e., } \\
& d\left(F x_{2 n}, T v\right) \preceq \frac{\lambda K}{1-\lambda K} d\left(v, x_{2 n+1}\right) \ll \frac{\lambda K}{1-\lambda K} \frac{c(1-\lambda K)}{\lambda K}=c ; \\
& \text { - } d\left(F x_{2 n} T v\right) \preccurlyeq \lambda d\left(x_{2 w} T v\right) \leqslant \lambda K\left(d\left(x_{2 n}, v\right)+K d\left(v, F x_{2 n}\right)+K d\left(F x_{2 n} T v\right)\right), \text { i.e., } \\
& d\left(F x_{2 n}, T v\right) \preceq \frac{\lambda K}{1-\lambda K^{2}} d\left(x_{2 n}, v\right)+\frac{\lambda K^{2}}{1-\lambda K^{2}} d\left(v, x_{2 n+1}\right) \\
& \quad \ll \frac{\lambda K}{1-\lambda K^{2}} \frac{c\left(1-\lambda K^{2}\right)}{2 \lambda K}+\frac{\lambda K^{2}}{1-\lambda K^{2}} \frac{c\left(1-\lambda K^{2}\right)}{2 \lambda K^{2}}=c
\end{aligned}
$$

(since $1 \leq K \leq 2$, we have $0 \leq \lambda \leq 1 /(2 K) \leq 1 / K^{2}$, i.e., $1-\lambda K^{2}>0$ ); - $d\left(F x_{2 n}, T v\right) \leqslant \lambda d\left(v, F x_{2 n}\right)=\lambda d\left(v, x_{2 n+1}\right) \ll \lambda \cdot c / \lambda=c$.

In all these cases, we obtain that $F x_{2 n} \rightarrow T v$, as $n \rightarrow \infty$, that is $x_{n} \rightarrow T v, n \rightarrow \infty$. Since the limit of a convergent sequence in a CMTS is unique, we have that $v=T v$. Now, we have to prove that $F v=T v$. Since

$$
d(F v, v)=d(F v, T v) \preceq \lambda u(v, v),
$$

where

$$
\begin{aligned}
u(v, v) & \in\{d(v, v), d(v, F v), d(v, T v), d(v, T v), d(v, F v)\} \\
& =\{\theta, d(v, F v)\}
\end{aligned}
$$

Hence, we get the following cases: $d(F v, v) \leqslant \lambda \theta$ and $d(F v, v) \leqslant \lambda d(F v, v)$. According to $\left(p_{3}\right)$, it follows that $F v=v$, that is, $v$ is a common fixed point of $F$ and $T$. It can be easily verified that $v$ is the unique common fixed point of $F$ and $T$.

By using the same steps as in proof of Theorem 3.1, one can prove the following theorem.

Theorem 3.2. Let $(X, d)$ be a complete CMTS with constant $K>2$ relative to a solid cone P. Let $\{F, T\}$ be a pair of self-mappings on $X$ such that for some constant $\lambda \in(0,1 /$ $K^{2}$ ) for all $x, y \in X$ there exists

$$
u(x, y) \in\{d(x, y), d(x, F x), d(y, T y), d(x, T y), d(y, F x)\}
$$


such that the inequality $d(F x, T y) \leqslant \lambda u(x, y)$ holds. Then $F$ and $T$ have a unique common fixed point.

In the case of CMTS with constant $K=1$ we get the following corollary, which extends [[21], Theorem 2.1].

Corollary 3.1. Let $(X, d)$ be a complete cone metric space relative to a solid cone $P$. Let $\{F, T\}$ be a pair of self-mappings on $X$ such that for some constant $\lambda L(0,1 / 2)$ for all $x, y \in X$ there exists

$$
u(x, y) \in\{d(x, y), d(x, F x), d(y, T y), d(x, T y), d(y, F x)\},
$$

such that the inequality $d(F x, T y) \leqslant \lambda u(x, y)$ holds. Then $F$ and $T$ have a unique common fixed point.

Theorem 3.3. Let $(X, d)$ be a complete CMTS with constant $K \geq 1$ relative to a solid cone $P$. Let $\{S, T\}$ be a pair of self-mappings on $X$ such that there exist nonnegative constants $a_{i}, i=1, \ldots, 5$, satisfying

$$
a_{1}+a_{2}+a_{3}+2 K \max \left\{a_{4}, a_{5}\right\}<1, \quad a_{3} K+a_{4} K^{2}<1, \quad a_{2} K+a_{5} K^{2}<1,
$$

such that for all $x, y \perp X$ inequality

$$
d(S x, T y) \preceq a_{1} d(x, y)+a_{2} d(x, S x)+a_{3} d(y, T y)+a_{4} d(x, T y)+a_{5} d(y, S x)
$$

holds. Then $S$ and $T$ have a unique common fixed point.

Proof. Setting $F=G=I_{X}$ from [[19], Theorem 3.8] ( $I_{X}$ is the identity mapping on $\left.X\right)$ we get what is stated.

In the case of CMTS with constant $K=1$ we get the following corollary.

Corollary 3.2. Let $(X, d)$ be a complete cone metric space relative to a solid cone $P$. Let $\{S, T\}$ be a pair of self-mappings on $X$ such that there exist nonnegative constants $a_{i}$, $i=1, \ldots, 5$, satisfying $a_{1}+a_{2}+a_{3}+2 \max \left\{a_{4}, a_{5}\right\}<1$, such that for all $x, y L X$ inequality

$$
d(S x, T y) \preceq a_{1} d(x, y)+a_{2} d(x, S x)+a_{3} d(y, T y)+a_{4} d(x, T y)+a_{5} d(y, S x)
$$

holds. Then $S$ and $T$ have a unique common fixed point.

\section{Acknowledgements}

The authors were supported in part by the Serbian Ministry of Education and Science (projects \#174015, \#174024, and |||44006).

\section{Author details}

Department of Mathematics and Informatics, Faculty of Science, University of Kragujevac, Radoja Domanovića 12 34000 Kragujevac, Serbia ²Department of Mathematics, Faculty of Mechanical Engineering, University of Belgrade, Kraljice Marije 16, 11120 Belgrade, Serbia

\section{Authors' contributions}

All authors contributed equally and significantly in writing this paper. All authors read and approved the final manuscript.

\section{Competing interests}

The authors declare that they have no competing interests.

Received: 10 October 2011 Accepted: 6 March 2012 Published: 6 March 2012

\section{References}

1. Rzepecki, B: On fixed point theorems of Maia type. Publ Inst Math. 28(42):179-186 (1980)

2. Lin, SD: A common fixed point theorem in abstract spaces. Indian J Pure Appl Math. 18(8):685-690 (1987)

3. Zabrejko, PP: K-metric and K-normed linear spaces: survey. Collect Math. 48(4-6):825-859 (1997) 
4. Huang, LG, Zhang, X: Cone metric spaces and fixed point theorems of contractive mappings. J Math Anal Appl. 332(2):1468-1476 (2007). doi:10.1016/j.jmaa.2005.03.087

5. Deimling, SK: Nonlinear Functional Analysis. Springer-Verlag Berlin (1985)

6. Boyd, S, Vandenberghe, L: Convex Optimization. Cambridge University Press Cambridge (2004)

7. Vetro, P: Common fixed points in cone metric spaces. Circ Mat Palermo. 56, 464-468 (2007). doi:10.1007/BF03032097

8. Rezapour, Sh, Hamlbarani, R: Some notes on the paper "Cone metric spaces and fixed point theorems of contractive mappings". J Math Anal Appl. 345, 719-724 (2008). doi:10.1016/j.jmaa.2008.04.049

9. Abbas, M, Jungck, G: Common fixed point results for noncommuting mappings without continuity in cone metric spaces. J Math Anal Appl. 341, 416-420 (2008). doi:10.1016/j.jmaa.2007.09.070

10. Di Bari, C, Vetro, P: $\varphi$-pairs and common fixed points in cone metric spaces. Rend Circ Mat Palermo. 57, 279-285 (2008). doi:10.1007/s12215-008-0020-9

11. Ilić, D, Rakočević, V: Common fixed points for maps on cone metric space. J Math Anal Appl. 341(2):876-882 (2008). doi:10.1016/j.jmaa.2007.10.065

12. Ilić, D, Rakočević, V: Quasi-contraction on a cone metric space. Appl Math Lett. 22(5):728-731 (2009). doi:10.1016/j. aml.2008.08.011

13. Radenović, S: Common fixed points under contractive conditions in cone metric spaces. Comput Math Appl. $\mathbf{5 8}$ 1273-1278 (2009). doi:10.1016/j.camwa.2009.07.035

14. Jungck, G, Radenović, S, Radojević, S, Rakočević, V: Common fixed point theorems for weakly compatible pairs on cone metric spaces. Fixed Point Theory Appl 2009 (2009). Article ID 643840). doi:10.1155/2009/643840.

15. Samet, B: Cirić's fixed point theorem in a cone metric space. J Nonlinear Sci Appl. 3(4):302-308 (2010)

16. Janković, S, Golubović, Z, Radenović, S: Compatible and weakly compatible mappings in cone metric spaces. Math Comput Model. 52, 1728-1738 (2010). doi:10.1016/j.mcm.2010.06.043

17. Choudhury, BS, Metiya, N: The point of coincidence and common fixed point for a pair of mappings in cone metric spaces. Comput Math Appl. 60, 1686-1695 (2010). doi:10.1016/j.camwa.2010.06.048

18. Gajić, L, llić, D, Rakočević, V: On Ćirić maps with a generalized contractive iterate at a point and Fisher's quasicontractions in cone metric spaces. Appl Math Comput. 216(8):2240-2247 (2010). doi:10.1016/j.amc.2010.03.010

19. Cvetković, AS, Stanić, MP, Dimitrijević, S, Simić, S: Common fixed point theorems for four mappings on cone metric type space. Fixed Point Theory Appl 2011 (2011). Article ID 589725, 15 doi:10.1155/2011/589725

20. Cirić, Lj: On common fixed points in uniform spaces. Publ Inst Math. 24(38):39-43 (1978)

21. Samet, B: Common fixed point under contractive condition of Cirić's type in cone metric spaces. Appl Anal Discrete Math. 5, 159-164 (2011). doi:10.2298/AADM110206007S

doi:10.1186/1687-1812-2012-35

Cite this article as: Stanić et al: Common fixed point under contractive condition of Cirić's type on cone metric type spaces. Fixed Point Theory and Applications 2012 2012:35.

\section{Submit your manuscript to a SpringerOpen ${ }^{\circ}$ journal and benefit from:}

- Convenient online submission

- Rigorous peer review

- Immediate publication on acceptance

- Open access: articles freely available online

- High visibility within the field

- Retaining the copyright to your article

Submit your next manuscript at $\gg$ springeropen.com 